\title{
Comparative analysis of activins $A$ and $B$ in the adult mouse epididymis and vas deferens
}

\author{
Rukmali Wijayarathna1,2,3, David M de Kretser1,2, Rajini Sreenivasan, Helen Ludlow ${ }^{4}$, \\ Ralf Middendorff ${ }^{3}$, Andreas Meinhardt ${ }^{1,2,3}$, Kate L Loveland ${ }^{1,2}$ and Mark P Hedger ${ }^{1,2}$ \\ ${ }^{1}$ Hudson Institute of Medical Research, Clayton, Victoria, Australia, ${ }^{2}$ Department of Anatomy and Developmental \\ Biology, Monash University, Clayton, Victoria, Australia, ${ }^{3}$ Department of Anatomy and Cell Biology, Justus-Liebig- \\ University, Giessen, Germany and ${ }^{4}$ Oxford Brookes University, Oxford, UK \\ Correspondence should be addressed to R Wijayarathna; Email: rukmali.wijayarathna@monash.edu
}

\begin{abstract}
Activin A regulates testicular and epididymal development, but the role of activin B in the epididymis and vas deferens is unknown.

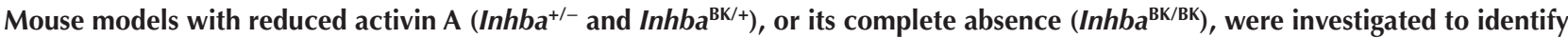
specific roles of activins in the male reproductive tract. In 8-week-old Inhba ${ }^{+/-}$mice, serum activin A decreased by $70 \%$, with a $50 \%$ reduction of gene expression and protein in the testis, epididymis and vas deferens. Activin B and the activin-binding protein, follistatin, were similar to wild-type. Testis weights were slightly reduced in Inhba ${ }^{+/-}$mice, but the epididymis and vas deferens were normal, while the mice were fertile. Activin A was decreased by $70 \%$ in the serum, testis, epididymis and vas deferens of Inhba ${ }^{\mathrm{BK} /+}$ mice and was undetectable in Inhba ${ }^{\mathrm{BK} / \mathrm{BK}}$ mice, but activin B and follistatin levels were similar to wild-type. In 6-week-old Inhba ${ }^{\mathrm{BK} / \mathrm{BK}}$ mice, testis weights were $60 \%$ lower and epididymal weights were $50 \%$ lower than in either Inhba ${ }^{\mathrm{BK} /+}$ or wild-type mice. The cauda epididymal epithelium showed infoldings and less intra-luminal sperm, similar to 3.5-week-old wild-type mice, but at 8 weeks, no structural differences in the testis or epididymis were noted between Inhba ${ }^{\mathrm{BK} / \mathrm{BK}}$ and wild-type mice. Thus, Inhbb can compensate for Inhba in regulating epididymal morphology, although testis and epididymal maturation is delayed in mice lacking Inhba. Crucially, reduction or absence of activin $A$, at least in the presence of normal activin B levels, does not lead to major defects in the adult epididymis or vas deferens.

Reproduction (2018) 155 15-23
\end{abstract}

\section{Introduction}

Activins belong to the transforming growth factorbeta (TGFB) superfamily of cytokines and regulate cell growth and differentiation in many tissues (Hedger \& de Kretser 2013). Activin A is composed of two inhibin beta A subunits, encoded by the Inhba gene (Vale et al. 1986, Robertson et al. 1987), and activin B is a dimer of inhibin beta B subunits, encoded by Inhbb (Nakamura et al. 1992). Inhibins are composed of an inhibin beta subunit and an -alpha subunit, encoded by the Inha gene, and act as antagonists of the activins (Robertson et al. 1985). Activin bioactivity is more widely regulated by the activin-binding protein, follistatin, which is encoded by the Fst gene (Robertson et al. 1987).

Activins act via classical TGFB signalling mechanisms involving heterodimeric serine-threonine kinase receptors (Wijayarathna \& de Kretser 2016). Initially, both activin $A$ and activin $B$ bind to an activin type 2 cell surface receptor (ACVR2A or ACVR2B). Activin $A$ and $B$ bind to type 2 receptors with equal affinity (Mathews \& Vale 1991). The type 2 receptor-protein complex recruits an activin type I receptor that initiates downstream signalling via the Smad2/3/4 signalling pathway. While activin $A$ recruits the type 1 receptor ALK4 (ACVR1B), activin B can recruit either ALK4 or ALK7 (ACVR1C) (Tsuchida et al. 2004). As a result of the ability to recruit both ALK4 and ALK7, activin B may possess a wider range of biological actions than activin A (de Kretser et al. 2012).

While activin A and B have substantially similar actions in most organ systems, the potency of each activin in regulating biological processes shows considerable variation. For example, while both activin $\mathrm{A}$ and $\mathrm{B}$ regulate embryonic mesoderm induction, activin B is more potent (Sokol et al. 1991, Nakamura et al. 1992). Furthermore, activin B plays a more important role in embryonic development of the central nervous system (Dutta et al. 2014, Feijen et al. 1994). On the other hand, activin A appears to be a more effective regulator of testicular development compared to activin $\mathrm{B}$, because $\operatorname{lnh} b \mathrm{a}^{\mathrm{BK} / \mathrm{BK}}$ mice, in which activin $\mathrm{A}$ has been replaced by an activin B-producing transgene, show a delay in testicular development (Brown et al. 2000) and altered postnatal germ cell maturation 
(Mithraprabhu et al. 2010). Moreover, activin B is a weaker agonist than activin $\mathrm{A}$ in regulation of $\mathrm{FSH}$ secretion by the anterior pituitary and in inducing erythroleukaemic cell differentiation (Nakamura et al. 1992).

The effects of activin A on testis development are relatively well-characterised (Barakat et al. 2008, Archambeault \& Yao 2010, Mithraprabhu et al. 2010, Mendis et al. 2011), but the roles of the activins in the remainder of the male tract have received much less attention. Both activin A and B proteins are produced in the epithelial lining of the epididymis and vas deferens in the adult mouse (Wijayarathna et al. 2017). The activins and follistatin are differentially expressed in the epididymis and vas deferens, with the highest level of activin $A$ and $B$ in the caput epididymis, and the highest level of follistatin in the vas deferens (Winnall et al. 2013, Wijayarathna et al. 2017). These observations suggest an interactive regulatory role for these proteins in the male reproductive tract, which is supported by the observation of structural and functional alterations in the epididymis and vas deferens of mice deficient in follistatin (Wijayarathna et al. 2017). Crucially, Inhba has been shown to be required for coiling of the anterior Wolffian duct during embryonic development of the mouse epididymis in mice lacking the Inhba gene $\left(\mathrm{Inhba}^{-/-}\right)$(Tomaszewski et al. 2007). Studies on the adult reproductive tract in the $\operatorname{lnhba}^{-1}$ mouse are limited by the fact that these mice die at birth. Moreover, the specific functional role of activin B in the epididymis and vas deferens has not been studied.

The effects of reduced Inhba expression and subsequent activin A deficiency in testicular development have been studied in Inhba ${ }^{+/-}$and Inhba ${ }^{\mathrm{BK} /}$ BK mice. The Inhba ${ }^{+-}$mouse bears only a single allele of the Inhba gene and hence produces reduced levels of activin A (Matzuk et al. 1995b). In the Inhba BK/ BK mouse, an Inhbb transgene has been inserted in the Inhba locus, with activin B completely replacing activin A (Brown et al. 2000). Decreased activin A levels in the Inhba ${ }^{+/}$mice resulted in a decrease in the number of Sertoli cells in the neonatal mouse testis (Mendis et al. 2011). Germ cell maturation and Sertoli cell proliferation in the juvenile Inhba $\mathrm{a}^{\mathrm{BK} / \mathrm{BK}}$ mouse testis were affected due to the complete absence of activin A (Mithraprabhu et al. 2010), and the Inhba ${ }^{\text {BK/BK }}$ mouse showed a 9-day delay on the onset of fertility due to delayed testis maturation (Brown et al. 2000). However, the rest of the male reproductive tract of these models has not been studied in depth, and the actual levels of activin $B$ in these mice have not been measured. This study utilised the Inhba ${ }^{+/-}$and Inhba ${ }^{\mathrm{BK} / \mathrm{BK}}$ mouse models to investigate the comparative roles of activin $A$ and activin $B$ in the regulation of the structure and function of the epididymis and vas deferens. Crucially, these studies provide evidence for a hitherto unidentified role for activin B in male reproductive tract function.

\section{Materials and methods}

\section{Animals and tissue collection}

Inhba ${ }^{+/-}$mice and Inhba ${ }^{\mathrm{BK} / \mathrm{BK}}$ mice were generated as described previously (Mithraprabhu et al. 2010, Mendis et al. 2011). All experiments were approved by the Animal Ethics Committee
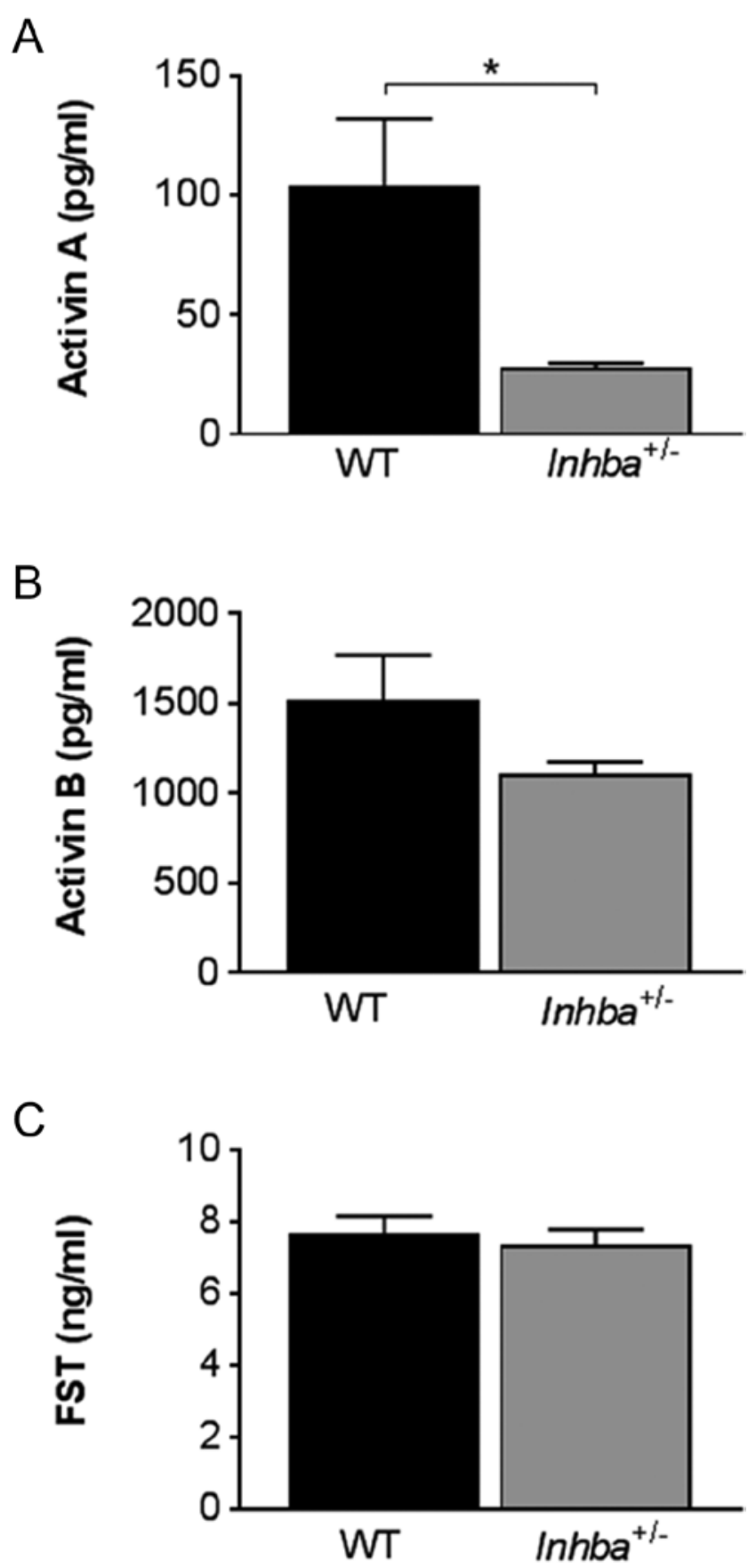

Figure 1 Serum activins and follistatin in adult $I n h b a^{+/}$mice. (A) Serum activin A, (B) activin B and (C) follistatin levels in 8-week-old Inhba ${ }^{+/-}$mice compared to wild-type (WT) littermates. $\left(n=8 \mathrm{WT}\right.$ and $\left.8 \mathrm{Inhba}^{+-}\right)$. Values are mean \pm S.E.M. Unpaired $t$-test. $* P<0.05$; Absence of statistical notation indicates that there were no significant differences between groups. 

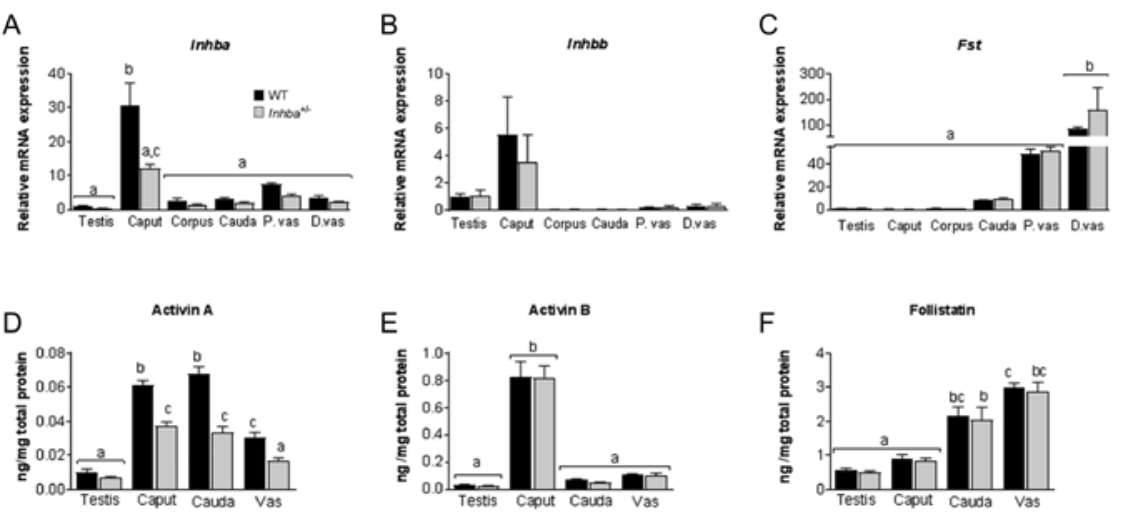

Figure 2 Activin A, B and follistatin gene and protein expression in the adult wild-type (WT) and Inhba ${ }^{+/-}$testis, epididymis and vas

deferens. (A) Inhba expression, measured in the testis, caput, corpus and cauda epididymis, and the proximal (P. vas) and distal (D. vas) segments of the vas deferens. (B) Inhbb gene expression. (C) Fst gene expression. (D) Activin A protein, (E) activin B protein and $(\mathrm{F})$ follistatin levels in the testis, caput and cauda epididymis and vas deferens $(n=4$ WT and 5 Inhba $\left.{ }^{+-}\right)$. Values are mean \pm S.E.M. Unpaired $t$-test. Tissues with different letter notations differ significantly $(P<0.05)$. Absence of statistical notation indicates that there were no significant differences between groups.
A

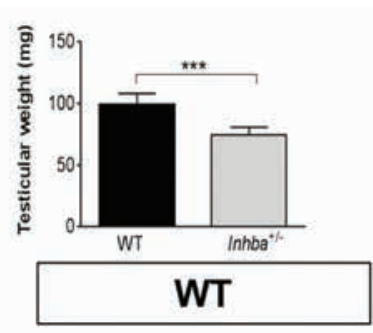

B

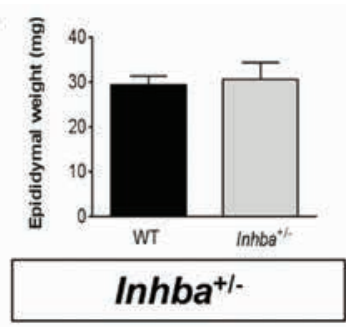

C
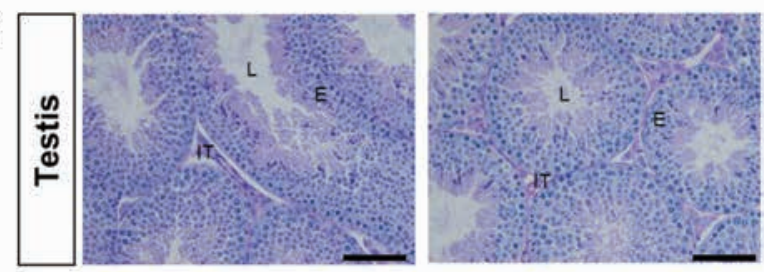

D
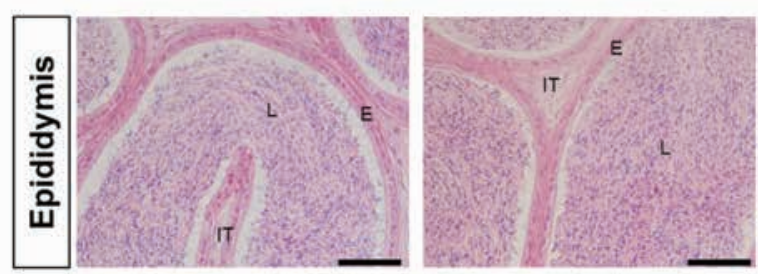

E
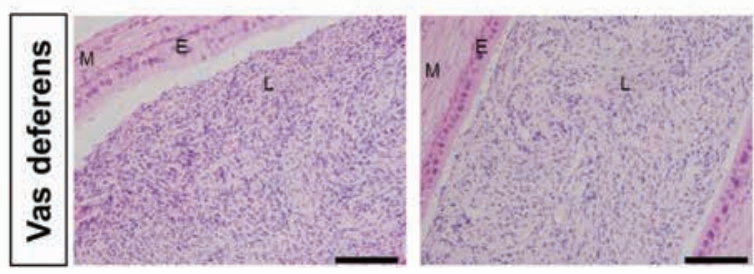

Figure 3 Adult Inhba ${ }^{+/-}$testicular and epididymal morphology. (A) Inhba ${ }^{+/-}$testicular weight and (B) epididymal weight compared with wild-type (WT) at 8 weeks of age. ( $n=8 \mathrm{WT}$ and 12 Inhba $^{+/-}$). Values are mean \pm S.E.M. Unpaired $t$-test. ${ }^{* * *} P<0.001$. (C) PAS-stained sections of WT and Inhba ${ }^{+/-}$testes. H\&E-stained sections of WT and Inhba ${ }^{+-}$, (D) cauda epididymis (segment 9) and (E) proximal region of the vas deferens. E, epithelium; IT, interstitial tissue; L, lumen; $M$, smooth muscle layer. Scale bar $=50 \mu \mathrm{m}$. of the Monash University, and were performed in accordance with guidelines of the NHMRC Code of Practice for the Care and Use of Animals for Experimental Purposes. Tissues from Inhba $\mathrm{h}^{+/}$mice and matching wild-type littermate controls were collected at eight weeks of age. Tissues from Inhba $a^{\mathrm{BK} / \mathrm{BK}}$ mice, heterozygous Inhba ${ }^{\mathrm{BK} /+}$ mice and matching wild-type littermates were collected at six weeks and eight weeks of age. During the collection of epididymides for protein and mRNA analyses, the organ was cut into 3 parts, guided by the clearly defined connective tissue boundaries between the segments: the caput (epididymal segments 1-5), corpus (segments 6-7) and cauda (segments 8-10) (Turner et al. 2003). Note that the caput includes the initial segment (segment 1 ) in all data presented. All tissues were collected and processed as described in Wijayarathna et al.(2017).

Fertility assessments were conducted by analysing breeding

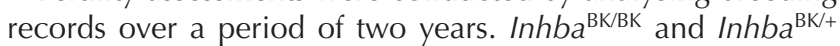
mice have reduced health and fertility compared with wildtype mice. Notably, Inhba ${ }^{\text {BK/BK }}$ mice, in particular, can die unexpectedly after 6 weeks, apparently due to complications arising from the absence of activin A (Brown et al. 2000, 2003). These fertility and viability issues limited the number of the Inhba $\mathrm{a}^{\mathrm{BK} / \mathrm{BK}}$ animals and corresponding tissues available for analysis, such as serum, epididymides and vasa deferentia for gene/protein analysis.

\section{Histology}

Bouin's fixed tissues were paraffin-embedded and longitudinally sectioned at $5 \mu \mathrm{m}$ thickness. Tissue sections were transferred to glass slides and stained using haematoxylin and eosin (H\&E) or Periodic acid-Schiff (PAS) protocols. Histological assessment of stained sections was performed using an Olympus BX50 microscope (Olympus) and the Cellsens dimensions software 1.7.1 (Olympus).

\section{Microarray and mRNA expression analysis}

Total RNA from the entire caput epididymis of 4 wild-type mice and $4 \mathrm{Inh} \mathrm{ha}^{+/-}$mice was extracted using the RNeasy kit (Qiagen) for microarray analysis. The RNA samples had an RNA integrity number of greater than or equal to 8.0. Cyanine-3 (Cy3)labelled cRNA was prepared from $0.2 \mu \mathrm{g}$ of total RNA using the 


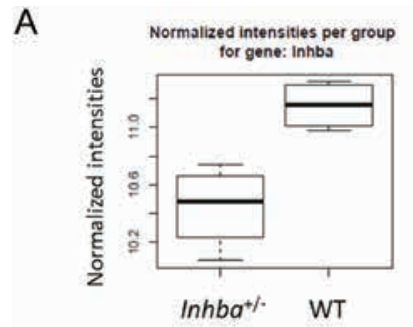

B

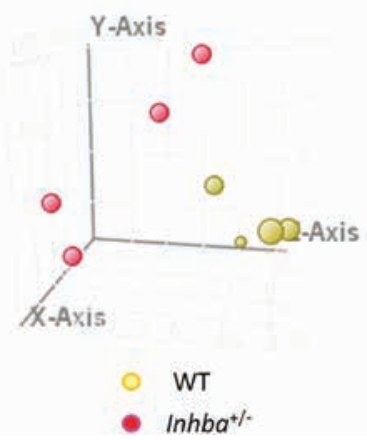

One-Color Low Input Quick Amp Labelling Kit (Agilent, v6.6 September 2012) according to the manufacturer's instructions, followed by Qiagen RNeasy column purification. 600 ng of Cy3-labelled cRNA (specific activity $>6$ pmol Cy3/ $\mu$ g cRNA) was fragmented and hybridised onto an Agilent SurePrint G3 Mouse gene expression $8 \times 60 \mathrm{~K}$ microarray slide (Design ID 028005) (Agilent Technologies). Slides were scanned on the Agilent DNA microarray scanner and the images were analysed with Feature Extraction Software 11.0.1.1 (Agilent). All array data were preprocessed using the R package limma (Smyth 2004), and Principal Component Analysis (PCA) was performed on the normalised data. Before proceeding with differential expression analysis, the normalised data for the 8 samples were filtered to remove invariant genes. Out of 55691 probe sets, 14672 probe sets having a variation coefficient greater than 0.03 across all samples were kept for further exploration. The normalised and filtered data were tested for significant differential expression between Inhba ${ }^{+/-}$and wildtype samples using the limma package (Smyth 2004). A linear model was fitted to the (log) normalised expression data and moderated $t$ statistics were computed and adjusted for multiple testing using the Benjamini and Hochberg method. Data analysis was also performed using the Agilent Gene Spring 12.0 software package as described inDairi et al. (2016).

In order to validate the microarray data, relative mRNA expression of Inhba, Inhbb, Fst, Ido1, Cox2, Hox10 and I/10 in the epididymal caput was measured by qRT-PCR using the same primer sequences and conditions described inWijayarathna et al. (2017). Furthermore, these genes were measured by qRT-PCR in the corpus and cauda epididymis and vas deferens, as well.

\section{Immunoassays for protein measurements}

Activin A was measured in serum and tissue lysates using a specific activin A ELISA employing antibodies supplied by Oxford Brookes University, as described previously
(Knight et al. 1996, O'Connor et al. 1999). The limit of detection was $33.2 \mathrm{pg} / \mathrm{mL}$. The mean inter-assay coefficient of variation (CV) was $8.6 \%$, while the mean intra-assay CV was $8.7 \%$.

Activin B was measured in serum and tissue lysates were assayed using a specific activin B ELISA, as reported by Ludlow and coworkers, using antibodies from Oxford Brookes University (Ludlow et al. 2009). The assay was validated for measurement of activin B in mouse tissues. The limit of detection was $28.4 \mathrm{pg} / \mathrm{mL}$. The mean inter-assay CV was $9 \%$ and the mean intra-assay $\mathrm{CV}$ was $9.6 \%$.

Total follistatin in serum and tissue lysates was measured using a discontinuous radioimmunoassay, as previously described (O'Connor et al. 1999, Winnall et al. 2013). This assay measures both forms of follistatin, produced by alternative splicing. The assay detection limit was $0.6 \mathrm{ng} / \mathrm{mL}$. The mean intra-assay CV was $10.3 \%$.

\section{Statistical analysis}

Statistical tests were conducted using Graphpad Prism 6 software (Graphpad Software). Student's t-test (two-tailed distribution) was used for comparisons between two groups. Multiple groups were compared using either one-way or two-way analysis of variance depending on the number of variables, followed by Tukey's multiple comparison test. Statistical significance was achieved when $P<0.05$. All data are presented as mean \pm standard error of mean (S.E.M.).

\section{Results}

\section{Activin $B$ and follistatin levels in serum were maintained in Inhba ${ }^{+/-}$mice, despite a reduction in activin $A$}

The Inhbat- mice showed a $70 \%$ reduction in serum activin $A$ levels relative to wild-type littermates at 8 weeks of age (Fig. 1A). Although serum activin B levels 
A
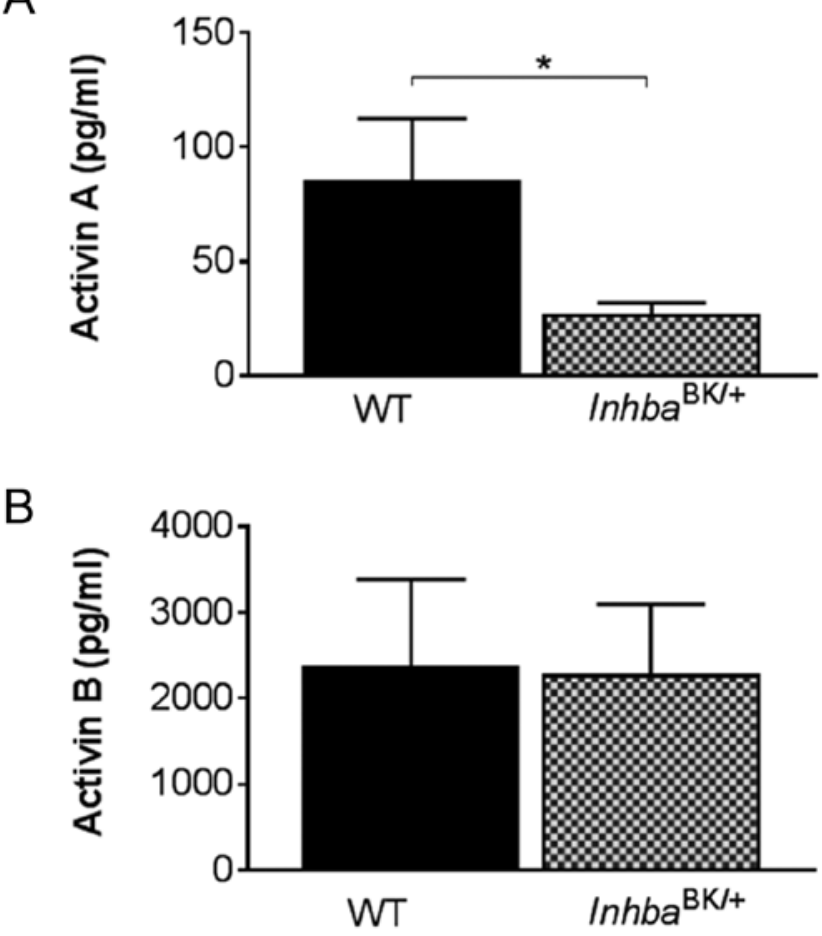

C

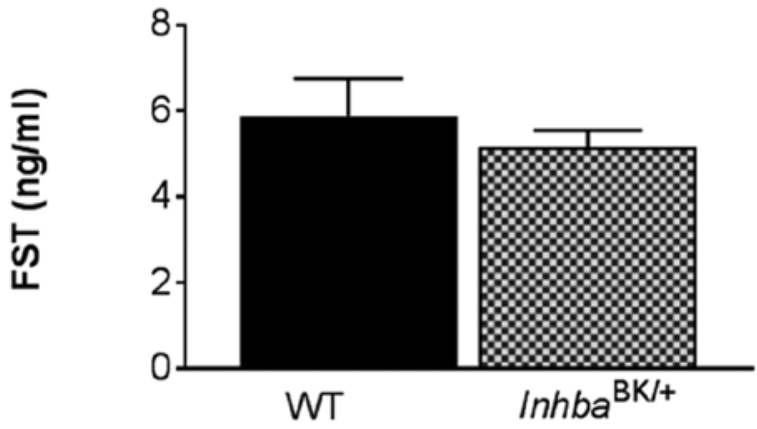

Figure 5 Serum activins and follistatin in adult Inhba ${ }^{\mathrm{BK} /+}$ mice. (A) Serum activin A, (B) activin B and (C) follistatin levels in 8-week-old Inhba ${ }^{\mathrm{BK} /+}$ mice compared with wild-type (WT) littermates $\left(n=4 \mathrm{WT}\right.$ and $\left.4 \mathrm{Inhba} \mathrm{a}^{\mathrm{BK} /+}\right)$. Values are mean \pm S.E.M. Unpaired $t$-test.

$* P<0.05$. Absence of statistical notation indicates that there were no significant differences between groups.

in Inhba $a^{+/}$mice showed an apparent small reduction compared to wild-type mice, this difference was not statistically significant (Fig. 1B). Serum follistatin levels were also similar to the wild-type (Fig. 1C).

\section{Activin $B$ and follistatin gene and protein levels were maintained in the male reproductive tract of Inhba $^{+/-}$mice}

Inhba expression, measured in the testis, caput, corpus and cauda epididymis, and the proximal and distal segments of the vas deferens, showed approximately a $50 \%$ reduction relative to wild-type littermates at 8 weeks of age (Fig. 2A). In contrast, Inhbb gene expression (Fig. 2B) was similar to that of the wild-type throughout the male reproductive tract. Both Inhba and Inhbb showed their highest expression in the caput region. In both wild-type and Inhba ${ }^{+-}$mice, the maximum level of Fst gene expression was found in the vas deferens (Fig. 2C).

Consistent with the reduced expression of Inhba, activin A protein levels showed a 50\% reduction throughout the testis, caput and cauda epididymis and vas deferens of Inhba ${ }^{+/}$mice (Fig. 2D). Activin B protein also followed the Inhbb expression, and was the highest in the caput region, similar to the wild-type (Fig. 2E). Activin B showed a much more restricted distribution pattern than that of activin A downstream of the caput epididymis. Follistatin protein levels in the testis, epididymis and vas deferens were similar to the wild-type, and largely followed the Fst gene expression pattern, despite the difference observed in the gene expression within the distal vas deferens.

\section{Adult testicular weight was decreased but no histological abnormalities were observed in the testis, epididymis or vas deferens of Inhba ${ }^{+/-}$mice}

At 8 weeks of age, testicular weight showed a small reduction $(20 \%)$ in the Inhba $^{+-}$mice compared to wild-type (Fig. 3A). Nevertheless, no differences were observed in sections of the testes of $\mathrm{Inhba}^{+/}$mice compared to wild-type controls at the histological level (Fig. 3C); the mice produced sperm and were fertile. The seminal vesicle weight of Inhba ${ }^{+/-}$mice was similar to that of wild-type littermates (data not shown), indicating that peripheral testosterone levels were normal.

The epididymal weight of Inhba ${ }^{+-}$mice was comparable to the wild-type at the age of 8 weeks (Fig. 3B). Histologically, the epididymis of Inhbat/- mice showed no evidence of defects in coiling of the duct, reduction in epididymal weight or any other type of morphological abnormality (Fig. 3D). Similarly, the vas deferens of Inhba ${ }^{+/-}$mice was histologically identical to the wild-type (Fig. 3E).

\section{Total gene expression in caput epididymis of Inhba $^{+/-}$ mice did not differ significantly from the wild-type}

Microarray analysis of $\sim 60,000$ transcripts of the caput epididymis showed that despite a $50 \%$ reduction in Inhba expression in this tissue (Fig. 4A), no statistically significant differences (adjusted $P$-value $<0.05$ ) were found in gene expression between Inhba ${ }^{+/}$and wildtype. Furthermore, PCA analysis did not identify grouping of the Inhba ${ }^{+/}$and wild-type samples (Fig. 4B). Similarly, a heat map of the top 500 genes based on the log fold change value did not show clustering of samples based on the genotypes (Fig. 4C). Crucial highly expressed epididymal functional genes, including 

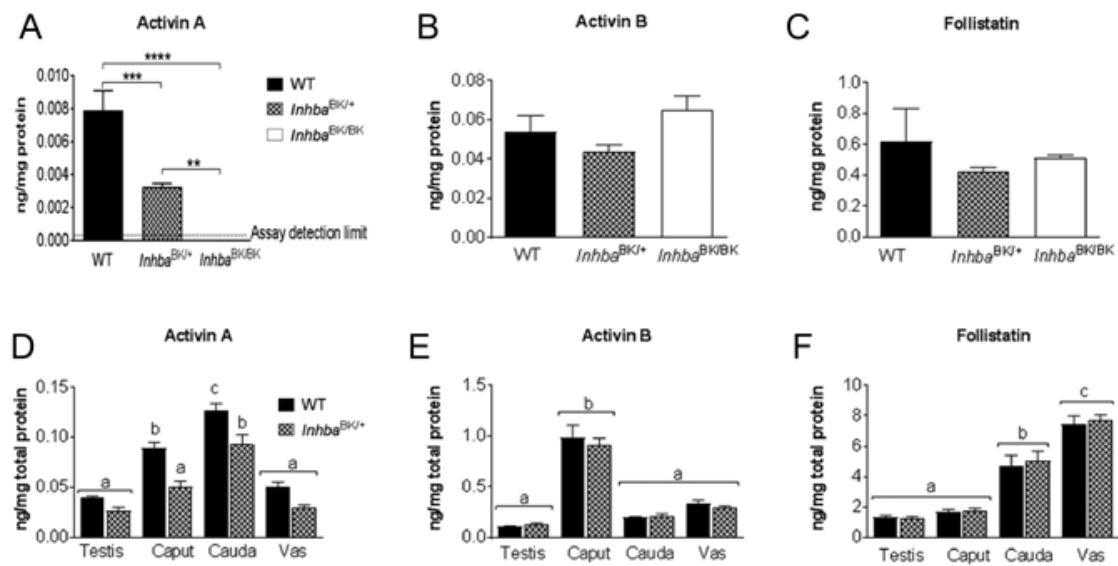

E

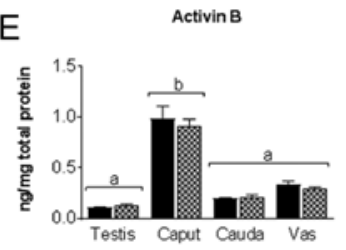

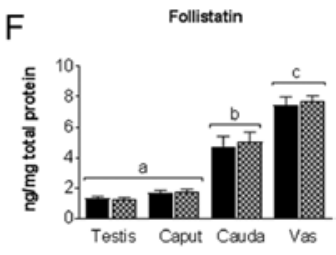

Figure 6 Activin A, B and follistatin protein expression in the adult wild-type (WT), Inhba ${ }^{\mathrm{BK} /+}$ and Inhba $\mathrm{B}^{\mathrm{BK} / \mathrm{BK}}$ testis, epididymis and vas deferens. (A) Activin A, (B) activin B and (C) follistatin protein in Inhba ${ }^{\mathrm{B} / B K}$ testicular lysates compared with those of Inhba ${ }^{\mathrm{BK} /+}$ and WT mice at the age of 8 weeks ( $n=5 \mathrm{WT}$, 6 Inhba $a^{\mathrm{BK} /+}$ and 4 Inhba ${ }^{\mathrm{BK} / \mathrm{BK}}$ ). (D) Activin A, (E) activin $B$ and $(F)$ follistatin protein in Inhba ${ }^{\mathrm{BK} /+}$ testis, epididymis and vas deferens

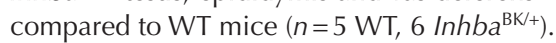
Values are mean \pm S.E.M. Unpaired $t$-test. Tissues with different letter notations differ significantly $(P<0.05) .{ }^{* * * *} P<0.0001$, ${ }^{* * *} P<0.001, * * P<0.01$. Absence of statistical notation indicates that there were no significant differences between groups. aquaporins (Aqp1-Aqp9, Aqp11, Aqp12), tight junction proteins (Tjp1-Tjp3) and caput-specific beta-defensins Defb41 and Defb42 (Jalkanen et al. 2005), were not differentially expressed. Moreover, preliminary qRTPCR expression analysis on known and putative activinresponsive genes such as Ido1, Cox2, Hox 10 and $/ / 10$ (Nüsing et al. 1995, Ciarmela et al. 2008, Wijayarathna et al. 2017) also did not show a difference between the genotypes (data not shown).

Altogether, the morphological, histological and gene expression data indicated that a 50\% reduction in activin A expression in the Inhba ${ }^{+/-}$mouse had no substantial effects on the structure and function of the
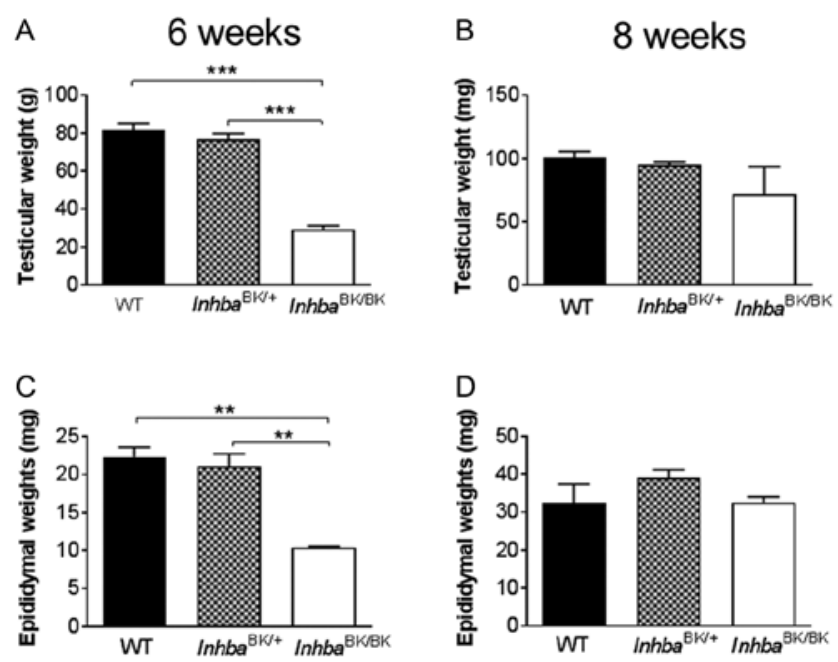

Figure 7 Testicular and epididymal weight of wild-type (WT), $\operatorname{Inh} b \mathrm{a}^{\mathrm{BK} /+}$ and Inhba $\mathrm{B}^{\mathrm{BK} / \mathrm{BK}}$ mice at 6 weeks and 8 weeks compared with controls. Testicular weights of Inhba ${ }^{\mathrm{BK} / \mathrm{BK}}$ mice compared with Inhba ${ }^{\mathrm{BK} /+}$ and WT littermates at (A) 6 weeks and (B) 8 weeks. (C) Epididymal weight at 6 weeks and (D) 8 weeks $(n=5-6 \mathrm{WT}$, 6 Inhba ${ }^{\mathrm{BK} /+}$ and 2-3 Inhba ${ }^{\mathrm{BK} / \mathrm{BK})}$. Values are mean \pm S.E.M. Unpaired $t$-test. ${ }^{* * *} P<0.001$. Absence of statistical notation indicates that there were no significant differences between groups. mature epididymis or vas deferens. Since these mice had essentially normal levels of activin B, the relative contributions of activin A and activin B were examined further in mice in which the Inhba gene had been partially $\left(I n h b a^{\mathrm{BK} /+}\right)$ or completely (Inhba $\left.{ }^{\mathrm{BK} / \mathrm{BK}}\right)$ replaced by Inhbb.

Inhba ${ }^{B K /+}$ mice had reduced activin $A$, but normal serum activin $B$ and follistatin levels, with normal activin $B$ and follistatin levels in the testes of both Inhba ${ }^{B K /+}$ and Inhba ${ }^{B K / B K}$ mice

At 8 weeks of age, Inhba $a^{\mathrm{BK} /+}$ mice showed a $60 \%$ decrease in serum activin $\mathrm{A}$ (Fig. 5A) and 50\% reduction in testicular activin A (Fig. 6A). As observed in Inhba ${ }^{+/-}$ mice, serum activin B (Fig. 5B) and follistatin (Fig. 5C) were similar to the wild-type (Fig. 5C). Insufficient blood samples were available for analysis from Inhba ${ }^{\mathrm{BK} / \mathrm{BK}}$ mice. Testicular activin B and follistatin were not different from the wild-type in the $\operatorname{Inh} b a^{\mathrm{BK} /+}$ and $\operatorname{Inh} b a^{\mathrm{BK} / \mathrm{BK}}$ mice at 8 weeks of age (Fig. 6A, B and C) or at 6 weeks of age (data not shown).

\section{Inhba ${ }^{B K /+}$ mice showed reduced activin $A$, but normal activin $B$ and follistatin levels in the epididymis and vas deferens}

In the Inhba ${ }^{\mathrm{BK} /+}$ mice at 8 weeks of age, the levels of activin A showed a 50\% reduction in the testis, caput and cauda epididymis, and vas deferens relative to the wild-type (Fig. 6D). Similar to the observation in the Inhba ${ }^{+-}$mice and their wild-type littermates, activin B protein levels were similar to the wild-type, and highest within the caput region of the Inhba $a^{\mathrm{BK} /+}$ mice (Fig. 6E). Follistatin protein levels were similar to the wild-type throughout the reproductive tract of the Inhba $a^{\mathrm{BK} /+}$ mice (Fig. 6F). Insufficient samples from the Inhba ${ }^{\mathrm{BK} /}$ ${ }^{B K}$ mice were available to measure protein levels in the epididymis and vas deferens. 

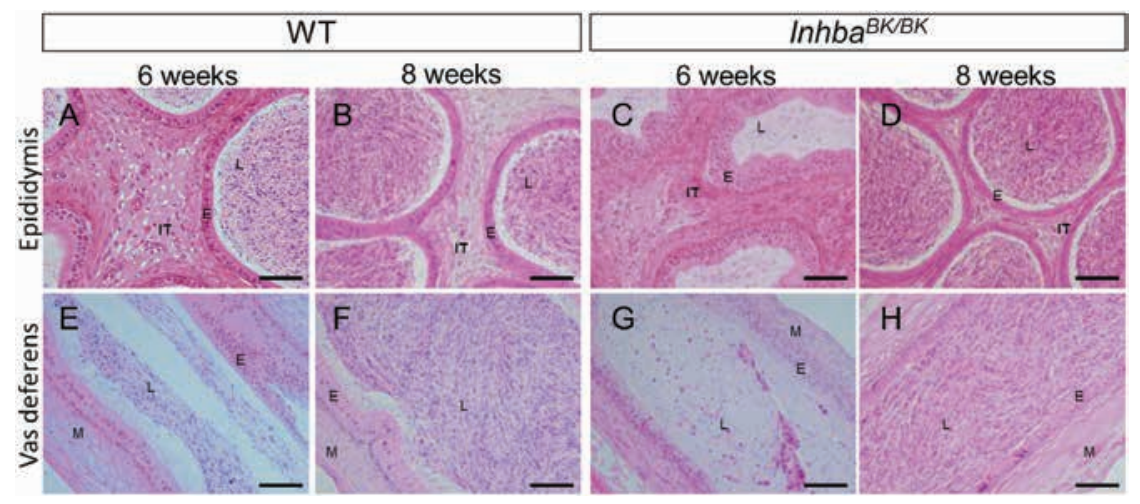

Figure 8 Histological assessment of the wild-type (WT) and Inhba ${ }^{\mathrm{BK} / \mathrm{BK}}$ epididymis and vas deferens. WT cauda epididymis (segment 9) at the age of (A) 6 weeks and (B) 8 weeks, compared to the Inhba ${ }^{\mathrm{BK} / \mathrm{BK}}$ cauda at (C) 6 weeks and (D) 8 weeks. Proximal region of the vas deferens in WT mice at (F) 6 weeks and $(\mathrm{G}) 8$ weeks, and Inhba ${ }^{\mathrm{BK} / \mathrm{BK}}$ mice at $(\mathrm{H})$ 6 weeks and (I) 8 weeks. H\&E-stained sections. Scale bar $=50 \mu \mathrm{m}$.

\section{The epididymis and vas deferens of the Inhba ${ }^{B K / B K}$ mice were not mature at 6 weeks of age, consistent with a developmental delay in the maturation of the testis}

At 8 weeks of age, the testis and epididymal weights of the Inhba $a^{\mathrm{BK} / \mathrm{BK}}$ mice were comparable to the Inhba ${ }^{\mathrm{BK} /+}$ and wild-type mice (Fig. 7B and D). However, at 6 weeks of age, when wild-type mice are sexually mature, the testis and epididymal weights of the Inhba ${ }^{\mathrm{BK} / \mathrm{BK}}$ mice were reduced by $\sim 60 \%$ and $50 \%$, respectively, relative to Inhba $\mathrm{BK}^{\mathrm{B}++}$ and wild-type littermates (Fig. 7A and C). This observation is consistent with the developmental delay in the Inhba ${ }^{\mathrm{BK} / \mathrm{BK}}$ testis, reported previously (Brown et al. 2000). Seminal vesicle weight, however, did not differ between the genotypes at either age examined (data not shown), indicating that the mice had normal androgen levels.

The Inhba ${ }^{\mathrm{BK} / \mathrm{BK}}$ epididymis at 8 weeks of age was histologically normal, with no evidence of reduced formation and coiling of the duct. At 6 weeks of age, however, the cauda epididymal epithelium in the Inhba ${ }^{\mathrm{BK} / \mathrm{BK}}$ mice was taller and had extensive folding (Fig. 8C), compared with the wild-type epithelium at this age (Fig. 8A). The amount of sperm present in the cauda epididymis of the Inhba ${ }^{\mathrm{BK} / \mathrm{BK}}$ mice at 6 weeks of age was also considerably reduced compared with the wildtype. The histological appearance of the epididymis of the Inhba ${ }^{\mathrm{B} / \mathrm{BK}}$ mice at 6 weeks of age was similar to a wild-type epididymal epithelium at the age of 3.5 weeks (data not shown). However, at the age of 8 weeks, the Inhba ${ }^{\mathrm{BK} / \mathrm{BK}}$ cauda epididymis was comparable to the wild-type both in terms of epithelial morphology and sperm content (Fig. 8B and D).

The vas deferens of $\operatorname{lnhba}{ }^{\mathrm{BK} / \mathrm{BK}}$ mice at 6 weeks of age also showed reduced sperm content and a large number of round cells, which were most likely prematurely released immature germ cells (Fig. 8H). At 8 weeks, the Inhba $a^{\mathrm{BK} / \mathrm{BK}}$ vas deferens was indistinguishable from the wild-type (Fig. 8G and I). The Inhba ${ }^{\mathrm{BK} /+}$ epididymis and vas deferens were indistinguishable from the wildtype at both time points studied (data not shown). Overall, comparison of the morphology of the testis and epididymis of the $\operatorname{lnh} b a^{\mathrm{BK} / \mathrm{BK}}$ mouse at 6 weeks and 8 weeks of age was consistent with delayed maturation, relative to the wild-type and Inhba ${ }^{\mathrm{BK} /+}$ mice, which were already mature by 6 weeks of age.

\section{Discussion}

This study is the first to highlight the functional significance of activin B in the structural development of the murine epididymis. Using a specific activin B immunoassay, our data established that the caput epididymis contains the highest activin B protein levels, confirming our earlier report based on immunohistochemistry (Wijayarathna et al 2017). Consistent with previous data, the highest Inhba gene expression in the male reproductive tract was also found in the caput epididymis of the adult mouse, but activin A protein levels were more broadly distributed downstream (Winnall et al. 2013, Wijayarathna et al. 2017). As activin B showed a more restricted distribution pattern downstream of the caput epididymis, this suggests that the clearance of activin B in the epididymis may be more efficient compared with activin A.

The high levels and regionalised expression of both activins $A$ and $B$ within the epididymis suggest critical roles for these proteins in epididymal development and function. Inhba is known to be an important regional paracrine regulator in the morphogenesis of the straight anterior Wolffian duct into the highly coiled epididymis. Tomaszewski and colleagues reported in 2007 that the Wolffian duct in Inhba $\mathrm{a}^{--}$mice, which completely lacked activin A, did not elongate and coil at E19.5 during development. Inhba ${ }^{-1}$ mice die at birth (Matzuk et al. 1995a), so their postnatal epididymal phenotype could not be studied. We show here that Inhba ${ }^{\mathrm{BK} / \mathrm{BK}}$ mice, in which the Inhba locus is replaced by Inhbb, displayed normal formation and coiling of the mature epididymis. This indicates that Inhbb, in the absence of Inhba, plays a compensatory role in anterior Wolffian duct coiling and epididymal development. At 6 weeks of age, a lag in Inhba ${ }^{\mathrm{BK} / \mathrm{BK}}$ epididymal development was observed in the form of epithelial immaturity and reduced organ weight, compared to wild-type mice. This is consistent with the previous observation of a maturational delay of the testis in the Inhba ${ }^{\mathrm{BK} / \mathrm{BK}}$ mice (Brown et al. 2000). Nevertheless, 
the Inhba ${ }^{\mathrm{BK} / \mathrm{BK}}$ epididymis was structurally comparable to the wild-type at the age of 8 weeks, providing further evidence that the lack of Inhba delays but does not completely prevent normal epididymal morphogenesis and development. This indicates that activin B can ultimately compensate for the complete lack of activin A in maintaining normal adult epididymal structure.

The mild hypogonadism seen in the Inhba ${ }^{+-}$mouse model does not cause overall fertility defects, as previously reported (Matzuk et al. 1995a). The reduction in adult testicular weight could be related to the decrease in Sertoli cell numbers observed in neonatal Inhba $\mathrm{h}^{+/-}$ mice (Mendis et al. 2011). The absence of morphological abnormalities in the epididymis of $\operatorname{Inhba}^{+/-}$mice is also reflected in the lack of transcriptomic differences between Inhbat/- and wild-type caput epididymis. It was noted that substantial variation existed among individual samples used for the microarray analysis even among wild-type individuals, as evident from the heatmap. Hence, it is possible that a larger sample size could perhaps detect significant gene expression differences. The lack of effects of reduced activin A on adult epididymal and vas deferens morphology or gene expression in this study contrasts with the pronounced effects of increased activin A on epididymal and vas deferens morphology and gene expression in the follistatin-288 deficient mouse model (Wijayarathna et al 2017). However, it is important to note that more subtle effects of reduced activin A on epididymal and vas deferens function may yet be found by a more detailed functional analysis.

\section{Declaration of interest}

The authors declare that there is no conflict of interest that could be perceived as prejudicing the impartiality of the research reported.

\section{Funding}

This study was funded by the National Health and Medical Research Institute of Australia to M P H, D M de K and K A L, the Victorian Government's Operational Infrastructure Support Program and the Deutsche Forschungsgemeinschaft (DFG, Germany) (GRK 1871/1).

\section{Acknowledgements}

The authors thank Jodee Gould and Roxane Legaie of the MHTP Medical Genomics Facility and Susan Hayward for their expert assistance, and the Oxford Brookes University for the antibodies used in the activin A and activin B assays.

\section{References}

Archambeault DR \& Yao HH 2010 Activin A, a product of fetal Leydig cells, is a unique paracrine regulator of Sertoli cell proliferation and fetal testis cord expansion. PNAS 107 10526-10531. (https://doi.org/10.1073/ pnas.1000318107)

Barakat B, O'Connor AE, Gold E, de Kretser DM \& Loveland KL 2008 Inhibin, activin, follistatin and FSH serum levels and testicular production are highly modulated during the first spermatogenic wave in mice. Reproduction 136 345-359. (https://doi.org/10.1530/REP-080140)

Brown CW, Houston-Hawkins DE, Woodruff TK \& Matzuk MM 2000 Insertion of Inhbb into the Inhba locus rescues the Inhba-null phenotype and reveals new activin functions. Nature Genetics 25 453-457. (https:// doi.org/10.1038/78161)

Brown CW, Li L, Houston-Hawkins DE \& Matzuk MM 2003 Activins are critical modulators of growth and survival. Molecular Endocrinology 17 2404-2417. (https://doi.org/10.1210/me.2003-0051)

Ciarmela P, Wiater E \& Vale W 2008 Activin-A in myometrium: characterization of the actions on myometrial cells. Endocrinology 149 2506-2516. (https://doi.org/10.1210/en.2007-0692)

Dairi G, Guan Q, Roshan-Moniri M, Collins CC, Ong CJ, Gleave ME, Nguan CY \& Du C 2016 Transcriptome-based analysis of molecular pathways for clusterin functions in kidney cells. Journal of Cellular Physiology 231 2628-2638. (https://doi.org/10.1002/jcp.25415)

de Kretser DM, O'Hehir RE, Hardy CL \& Hedger MP 2012 The roles of activin $\mathrm{A}$ and its binding protein, follistatin, in inflammation and tissue repair. Molecular and Cellular Endocrinology 359 101-106. (https://doi. org/10.1016/j.mce.2011.10.009)

Dutta DJ, Zameer A, Mariani JN, Zhang J, Asp L, Huynh J, Mahase S, Laitman BM, Argaw AT, Mitiku N et al. 2014 Combinatorial actions of Tgf $\beta$ and Activin ligands promote oligodendrocyte development and CNS myelination. Development 141 2414-2428. (https://doi. org/10.1242/dev.106492)

Feijen A, Goumans MJ, van den AJ \& Raaij E-V 1994 Expression of activin subunits, activin receptors and follistatin in postimplantation mouse embryos suggests specific developmental functions for different activins. Development 120 3621-3637.

Hedger MP \& de Kretser DM 2013 The activins and their binding protein, follistatin-Diagnostic and therapeutic targets in inflammatory disease and fibrosis. Cytokine and Growth Factor Reviews 24 285-295. (https:// doi.org/10.1016/j.cytogfr.2013.03.003)

Jalkanen J, Huhtaniemi I \& Poutanen M 2005 Discovery and characterization of new epididymis-specific beta-defensins in mice. Biochimica et Biophysica Acta 1730 22-30. (https://doi.org/10.1016/j. bbaexp.2005.05.010)

Knight PGMuttukrishna S Groome NP1996 Development and application of a two-site enzyme immunoassay for the determination of 'total' activin-A concentrations in serum and follicular fluid. Journal of Endocrinology 148 267-279. (https://doi.org/10.1677/joe.0.1480267)

Ludlow H, Phillips DJ, Myers M, McLachlan RI, De Kretser DM, Allan CA, Anderson RA, Groome NP, Hyvönen M, Colin Duncan W et al. 2009 A new 'total' activin B enzyme-linked immunosorbent assay (ELISA): development and validation for human samples. Clinical Endocrinology 71 867-873. (https://doi.org/10.1111/j.1365-2265.2009.03567.x)

Mathews LS \& Vale WW 1991 Expression cloning of an activin receptor, a predicted transmembrane serine kinase. Cell 65 973-982. (https://doi. org/10.1016/0092-8674(91)90549-E)

Matzuk MM, Kumar TR, Bickenbach JR, Vassalli A, Roop DR, Jaenisch R \& Bradley A 1995a Functional analysis of activins during mammalian development. Nature 374 354-356. (https://doi.org/10.1038/374354a0)

Matzuk MM, Kumar TR \& Bradley A 1995b Different phenotypes for mice deficient in either activins or activin receptor type II. Nature $\mathbf{3 7 4}$ 356-360. (https://doi.org/10.1038/374356a0)

Mendis SHS, Meachem SJ, Sarraj MA \& Loveland KL 2011 Activin A balances sertoli and germ cell proliferation in the fetal mouse testis. Biology of Reproduction 84 379-391. (https://doi.org/10.1095/ biolreprod.110.086231)

Mithraprabhu S, Mendis S, Meachem SJ, Tubino L, Matzuk MM, Brown CW \& Loveland KL 2010 Activin bioactivity affects germ cell differentiation in the postnatal mouse testis in vivo. Biology of Reproduction $\mathbf{8 2}$ 980-990. (https://doi.org/10.1095/biolreprod.109.079855)

Nakamura T, Asashima M, Eto $Y$, Takio K, Uchiyama H, Moriya N, Ariizumi T, Yashiro T, Sugino K, Titani K et al. 1992 Isolation and characterization of native activin B. Journal of Biological Chemistry 267 16385-16389. 
Nüsing RM, Mohr S \& Ullrich V 1995 Activin A and retinoic acid synergize in cyclooxygenase-1 and thromboxane synthase induction during differentiation of J774.1 macrophages. European Journal of Biochemistry 227 130-136.

O'Connor AEMcFarlane JRHayward SYohkaichiya TGroome NP de Kretser DM1999 Serum activin A and follistatin concentrations during human pregnancy: a cross-sectional and longitudinal study. Human Reproduction 14 827-832. (https://doi.org/10.1093/humrep/14.3.827)

Robertson DM, Foulds LM, Leversha L, Morgan FJ, Hearn MTW, Burger HG, Wettenhall REH \& de Kretser DM 1985 Isolation of inhibin from bovine follicular fluid. Biochemical and Biophysical Research Communications 126 220-226. (https://doi.org/10.1016/0006-291X(85)90594-7)

Robertson DM, Klein R, de Vos FL, McLachlan RI, Wettenhall REH Hearn MTW, Burger HG \& de Kretser DM 1987 The isolation of polypeptides with FSH suppressing activity from bovine follicular fluid which are structurally different to inhibin. Biochemical and Biophysical Research Communications 149 744-749. (https://doi.org/10.1016/0006291X(87)90430-X)

Smyth GK 2004 Linear models and empirical bayes methods for assessing differential expression in microarray experiments. Statistical Applications in Genetics and Molecular Biology 3 1-25. (https://doi. org/10.2202/1544-6115.1027)

Sokol S, Christian JL, Moon RT \& Melton DA 1991 Injected Wnt RNA induces a complete body axis in Xenopus embryos. Cell 67 741-752. (https://doi.org/10.1016/0092-8674(91)90069-B)

Tomaszewski J, Joseph A, Archambeault D \& Yao HHC 2007 Essential roles of inhibin beta A in mouse epididymal coiling. PNAS $10411322-11327$ (https://doi.org/10.1073/pnas.0703445104)

Tsuchida K, Nakatani M, Yamakawa N, Hashimoto O, Hasegawa Y \& Sugino H 2004 Activin isoforms signal through type I receptor serine/ threonine kinase ALK7. Molecular and Cellular Endocrinology 220 59-65. (https://doi.org/10.1016/j.mce.2004.03.009)
Turner T, Bomgardner D, Jacobs J \& Nguyen Q 2003 Association of segmentation of the epididymal interstitium with segmented tubule function in rats and mice. Reproduction 125 871-878. (https://doi. org/10.1530/rep.0.1250871)

Vale W, Rivier J, Vaughan J, McClintock R, Corrigan A, Woo W, Karr D \& Spiess J 1986 Purification and characterization of an FSH releasing protein from porcine ovarian follicular fluid. Nature 321 776-779. (https://doi.org/10.1038/321776a0)

Wijayarathna R \& de Kretser DM 2016 Activins in reproductive biology and beyond. Human Reproduction Update 22 342-357. (https://doi. org/10.1093/humupd/dmv058)

Wijayarathna R, Sarraj MA, Genovese R, Girling JE, Michel V, Ludlow H, Loveland KL, Meinhardt A, de Kretser DM \& Hedger MP 2017 Activin and follistatin interactions in the male reproductive tract: activin expression and morphological abnormalities in mice lacking follistatin 288. Andrology 5 578-588. (https://doi.org/10.1111/ andr.12337)

Winnall WR, Wu H, Sarraj MA, Rogers PAW, De Kretser DM, Girling JE \& Hedger MP 2013 Expression patterns of activin, inhibin and follistatin variants in the adult male mouse reproductive tract suggest important roles in the epididymis and vas deferens. Reproduction, Fertility and Development 25 570-580. (https://doi.org/10.1071/RD11287)

Received 4 August 2017

First decision 6 September 2017

Revised manuscript received 21 September 2017

Accepted 13 October 2017 